\title{
An innovative approach to the assessment of laypersons' knowledge of contraceptive methods, followed by an educational intervention
}

\author{
Marta Edna H D Yazlle, MD, PhD, Assistant Professor with Responsibility for Contraception; Maria Célia Mendes, MD, PhD, \\ Assistant Professor; Maristela C Patta, MD, PhD; Assistant Physician; Aderson T Berezowski, MD, PhD, Assistant Professor; \\ George D Azevedo, MD, Postgraduate Student; Alessandra C Marcolin, MD, Postgraduate Student, Department of Gynecology \\ and Obstetrics, Faculty of Medicine of Ribeirão Preto, University of São Paulo, Brazil
}

Correspondence: Prof. Dr Marta Edna H D Yazlle, Department of Gynecology and Obstetrics, Faculty of Medicine of Ribeirão Preto, University of São Paulo, Av. Bandeirantes 3900, Monte Alegre, 14049-900, Ribeirão Preto, SP, Brazil. Fax: +55 166330946

(Accepted 29 $9^{\text {th }}$ October 2003)

Journal of Family Planning and Reproductive Health Care 2003; 29(1): 37-38

\begin{abstract}
Objectives. To assess the knowledge of laypersons about contraceptive methods and to pilot an educational strategy. Design. Cross-sectional survey using an anonymous questionnaire followed by an educational intervention.

Participants. A total of 167 respondents to 400 invitations. Method. A questionnaire with 10 questions about contraceptive methods was answered before a meeting between laypersons and health professionals. Small groups facilitated by a health professional discussed the answers. One representative from each group presented the conclusions. At the end of the discussion session, gynaecologists gave lectures about contraceptive methods. Results. Of the 167 people who attended, only 65 (39\%) individuals handed over their anonymous answers for analysis. Those who did knew about the existence of contraceptive methods, but most of them showed incorrect or little knowledge about mechanism of action or risks.

Conclusion. Embarrassment led many participants not to hand in their questionnaires but the results were evidence of the need for educational interventions. Lessons learnt from this experience are discussed.
\end{abstract}

\section{Introduction}

We conducted the present study with the objective of using a method to assess the level of knowledge of individuals about contraceptive methods and then offer relevant information.

In Brazil, many people use contraceptive methods, with the exception of intrauterine devices (IUDs) and tubal ligation, on their own without consulting a health professional, and therefore without taking into consideration their possible risks.

The choice of a contraceptive method is determined by social factors and by the degree of knowledge that individuals have about these methods. ${ }^{1,2}$ In addition, some studies suggest that lack of knowledge, fear and religious beliefs may impair this choice. ${ }^{3}$ These previous studies indicate that education emphasising information on contraceptive methods may improve the use of these methods ${ }^{4}$ by influencing the decision-making process and contributing to treatment compliance. ${ }^{5,6}$ Individuals often end up using a method, even when it is not the most adequate one, due to lack of information or because they have acquired negative attitudes towards other methods. ${ }^{2}$

According to Virjo et al., ${ }^{7}$ the main information sources about contraceptives for women are books, medical information and women's magazines and for men, books and reports from their peers. The content of educational programmes should take into consideration what people need to know about methods and the level of knowledge they already have.

\section{Method}

A total of 400 invitations were distributed to men and women (who demonstrated an interest in participating) from worker associations, community centres, organised groups, firemen and military police. The invitation contained an explanation about the event, and a simple questionnaire about the types, modes of action and side effects of contraceptive methods. The participants were requested to bring the anonymous, completed questionnaires to the meeting. Small groups facilitated by a health professional discussed the answers. One representative from each group presented the conclusions. At the end of the discussion session, specialists gave userfriendly lectures about contraceptive methods.

The anonymous questionnaires were collected at the end of the meeting, however some of the respondents refused to hand them in because they felt embarrassed about having answered some questions incorrectly. After the symposium the answers to the questionnaires were evaluated by the authors.

\section{Results}

Out of 400 invitations, 167 individuals (42\%) attended the symposium with answered questionnaires. Of these 167 individuals, only $65(39 \%)$ handed over their answers for analysis. The others claimed that they had written their replies in an incorrect manner.

The contraceptive methods most frequently cited by the group who returned the questionnaires were oral hormonal contraceptives (OC) (94\%), condoms (86\%), intrauterine devices (IUDs) (66\%) and the rhythm method (63\%).

Knowledge about the mechanism of action of various methods was correct for female sterilisation (52\%) followed by OC (31\%), vasectomy (29\%) and then IUD (9\%). Knowledge of side effects or complications was demonstrated by $82 \%$ for OC, $59 \%$ for IUD, $38 \%$ for female sterilisation and $23 \%$ for vasectomy.

\section{Discussion}

Distributing the anonymous questionnaire with invitations was an innovative and unusual approach but may partly explain the low response to the meeting.

Analysis of the returned questionnaires showed that OC, condom and IUD were the contraceptive methods most frequently cited. Particularly noteworthy was the lack of information about the mechanism of action of the IUD, although most individuals reported its site of insertion correctly. A high percentage of individuals knew about OC 
side effects and complications, probably because OC is one of the most widely used methods. ${ }^{8,9}$ Although female sterilisation is widely used, many of the participants did not know about side effects or complications.

\section{Reflection}

We believe that in places where discussion about contraceptive methods is uncommon, initiatives using this type of educational strategy should be encouraged. They permit information to be given to a large number of people at the same time. It is also possible to find out what people already know and think about the subject.

One way to attract a larger number of people to activities of this type might be more effective marketing using attractive posters and invitations, which may mobilise the population to discuss questions regarding their health.

Of the total number of participants, only $65(39 \%)$ handed over their answers for analysis. People felt embarrassed about handing over incorrectly completed questionnaires, so it is likely that our results overestimate the level of knowledge in our study population. Information on the characteristics of responders and non-responders would have been interesting, but we wanted to keep the questionnaire anonymous and simple. The questionnaires could have been given to and completed by individuals at the beginning of the symposium and after a motivational session before starting the discussion. In this way it would have been possible to obtain information about individuals' previous knowledge before giving them the answers.

Although the number of responses evaluated was low, the data obtained indicated the necessity to implement educational measures which may contribute to improving the efficacy of projects in the area of contraception.
Preliminary studies evaluating the level of knowledge of the population on this subject are required to direct educational measures and in future post-intervention evaluation is also required.

Statements on funding and competing interests

Funding. None identified.

Competing interests. None identified.

References

1 Oddens BJ, Lehert P. Determinants of contraceptive use among women of reproductive age in Great Britain and Germany. I: Demographic factors. J Biosoc Sci 1997; 29: 415-435.

2 Oddens BJ. Determinants of contraceptive use among women of reproductive age in Great Britain and Germany. II: Psychological factors. J Biosoc Sci 1997; 29: 437-470.

3 Konje JC, Oladini F, Otolorin EO, et al. Factors determining the choice of contraceptive methods at the family planning clinic, University College Hospital, Ibadan, Nigeria. Br J Fam Plann 1998; 24: 107-110.

4 Bolam A, Manandhar DS, Shrestha P, et al. The effects of postnatal health education for mothers on infant care and family planning practices in Nepal: a randomised controlled trial. BMJ 1998; 316(7134): 805-811.

5 Oddens BJ. Contraceptive use and attitudes in Italy 1993. Hum Reprod 1996; 11(3): 533-539.

6 Little P, Glew C, Kelly J, et al. Contraceptive knowledge: development of a valid measure and survey of pill users and general practitioners. Br J Fam Plann 1998; 24: 98-100.

7 Virjo I, Kirkkola AL, Isokoski M, et al. Contraceptive methods: knowledge sources rated by women and men. Contraception 1999; 59: 257-263.

8 Mishell DR Jr. Contraception. In: Yen SSC, Jaffe RB, Barbieri RL (eds), Reproductive endocrinology (4th edn). Philadelphia, PA: Saunders Company, 1999, 676-708.

9 Melo NR, Aldrighi JM, Benzecry RM. Anticonceptional hormonal oral. In: Oliveira HC, Lengruber I (eds), Tratado de ginecologia, febrasgo, vol. I. Rio de Janeiro, RJ: Livraria e Editora Revinter Ltda, 2000, 407-421.

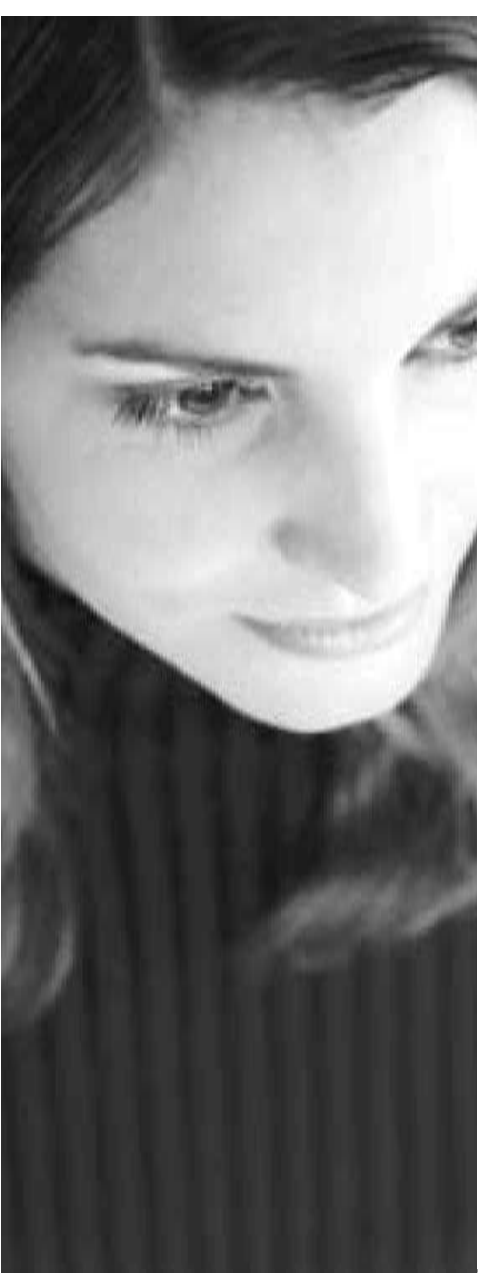

Termination of Pregnancy

\section{Fast, confidential, caring. The professional choice.}

Marie Stopes International is a leading charity in the field of family planning. We work closely with the NHS to provide termination of pregnancy services and are also happy to accept private referrals.

At centres around the UK we offer a professional and convenient service. You can trust us to take care of the patients you refer. We're discreet, confidential, sympathetic and will do everything we can to make a difficult time easier. Patients can also rely on our full aftercare service including post abortion counselling.

If your patient would like an appointment or if you would like to find out more about us, simply call the number below. We will be happy to send you an information pack containing full details of our services and some easy to use referral forms. Alternatively, you can visit our web site.

\section{Call us on 08453001212} or visit www.mariestopes.org.uk 